\title{
Floristic Diversity and Vegetation Structure of Coffee Agroforests in Relation to Natural Forests in Dry Deciduous Vegetation Zone in Central Western Ghats of India
}

\author{
Baliram G. Nayak ${ }^{1 *}$ and Raju L. Chavan² \\ ${ }^{1}$ Department of Silviculture and Agroforestry, College of Forestry, Sirsi- 581 401, India \\ ${ }^{2}$ University of Agricultural Sciences, Dharwad, Karnataka, India \\ *Corresponding author
}

\section{A B S T R A C T}

\section{Keywords \\ Coffee agroforests, Landholdings, \\ Floristic diversity, \\ Conservation, \\ Sustainability \\ Article Info \\ Accepted: \\ 17 June 2019 \\ Available Online: \\ 10 July 2019}

The objective of this study is to measure the floristic diversity in coffee agroforests and adjoining forests as well to know the effect of different landholding sizes of coffee farms in Kodagu district, Western Ghats of Karnataka. We collected the data on trees, shrubs and herbs from 50 sample plots of 0.16 ha. Each and analyzed for various diversity parameters. Results revealed that Shannon's $\left(H^{\prime}\right)$ was highest in adjoining forests (2.48) compared to that of coffee agroforests (1.92). On the other hand, Simpson's (D) value recorded in adjoining forests lower (0.11) compared to coffee agroforests (0.28). This study revealed that the considerable number of tree species are being managed and conserved in coffee agroforests, similar to that of adjoining natural forests. IVI revealed that Grevillea robusta was found to be most dominant species in coffee agroforests, while in natural forests, Terminalia tomentosa species was dominant. Considerable variation in various diversity parameters was noticed among different landholding sizes with higher diversity in medium holding compared to small and large sized coffee plantations. Contrary, higher basal area $\left(\mathrm{m}^{2} \mathrm{ha}^{-1}\right)$ was recorded in large farms compared to small and medium sized coffee farms. We found that coffee agroforests resembled to that of adjoining forests suggesting that traditional coffee farms are being managed sustainably and can help to conserve the biodiversity.

\section{Introduction}

Conservation of global biological diversity and ecosystem services has been given lot of emphasis by the scientists and policy makers to protect species extinction and ecosystem degradation while allowing for sustainable utilization of natural resources (Adams and Hulme, 2001). Even though the disappearance of species during natural process, the present rates of disappearance of species affected by human activities in the tropical region of rain forest were expected to be 1000 to 10,000 times greater than the normal rate (Berkes, 2009).

Western Ghats landscapes in peninsular India are the unique mosaics of natural forests 
interspersed with agricultural lands, coffee agroforests, tea plantations and various other tree-based production systems which are known to be the most species-diverse terrestrial ecosystems (Baghwat et al., 2008). The majority of the 36 global biodiversity hotspots identified worldwide occur within tropical regions and the Western Ghats in South India is one among them (Myers et al., 2000). Forests of Western Ghats contain the most diverse plant communities, with up to $350-400$ tree and liana species coexisting in a single hectare (Devagiri et al., 2012 and Murthy et al., 2016). In addition to the rich biodiversity, these forests are also acting as natural sinks of carbon, with a sequestration potential of $80-150 \mathrm{Mg} \mathrm{C} \mathrm{ha}^{-1}$ (Devagiri et al., 2013) and thus playing a fundamental role in the global carbon cycle. Among different land use systems, agroforestry is one of the important land use systems which is most prevalent in the Western Ghats region. In addition to enhancing the productivity of agricultural land, agroforestry systems have contributed to the conservation of biological diversity. Studies shown that in humid tropical landscapes, coffee agroforestry system has a conservation value comparable to that of natural forests (Baghwat et al., 2008).

Kodagu is one of the greenest landscapes in India and is part of the Western Ghats, with $81 \%$ of the geographical area under tree cover. The district harbors diverse ecosystems such as natural forests, sacred groves, coffee agroforests and forest plantations that contribute to the diversity of species representing $8 \%$ of India's plant wealth (Pascal and Pelissier, 1996 and Baghwat et al., 2005a and 2005b). This diverse landscape is undergoing transformations concerning biodiversity and canopy density due to the changed production system under the current liberalized market situation (Devagiri et al., 2012). There is a gradual increase in area under coffee agroforests, rubber and other tree species plantations (CAFNET, 2011). An assessment of change in forest cover of Kodagu district during the last 20 years between 1977 and 1997 indicated the decline in forest cover from an area of $2566 \mathrm{~km}^{2}$ to $1841 \mathrm{~km}^{2}$ representing a reduction of $18 \%$ of the total geographical area. A large part of it has been converted into coffee; teak and teak mixed with other tree species plantations (Elourd, 2000). To realize the opportunities for conservation outside the natural forest areas and to device conservation strategies, deeper knowledge on the level of diversity that exists in production landscapes such as coffee agroforests and other tree-based systems is very fundamental. Therefore, this study was conducted to know the species composition and floristic diversity in coffee agroforests of Kodagu district and to explore the opportunity for conservation in the production landscape in Central Western Ghats of India.

\section{Materials and Methods}

\section{Study area}

The study was conducted in forests-coffee agroforests landscape mosaics of Kodagu district during the year 2017-18, which lies in the Central Western Ghats region $\left(70^{\circ} 25^{\prime}\right.$ $76^{\circ} 14^{\prime} \mathrm{E}$ and $12^{\circ} 15^{\prime}-12^{\circ} 45^{\prime} \mathrm{N}$ ) covering an area of $4106 \mathrm{~km}^{2}$. The district shares a common border with Kerala in the south and is surrounded by three other districts of Karnataka viz., Dakshina Kannada, Hassan, and Mysore. The eastern border of Kodagu district extends over the Mysore plateau. It has a steep West to East climatic gradients especially, for temperature and rainfall from the edge of the Ghats (Elourd, 2000). The study area, with an altitudinal range of 3001300 m.a.s.l., receives average annual rainfall ranging from 1500 to $3500 \mathrm{~mm}$ with maximum rainfall during monsoon season (June to September). April and May record the 
highest mean maximum temperature $\left(32^{\circ} \mathrm{C}\right)$, while December and January will have the lowest mean minimum temperature $\left(15^{\circ} \mathrm{C}\right)$. Soils are lateritic to red loamy, which have a mature profile and main rock formation belongs to the most ancient Archaean system with rock composed of peninsular gneiss, gneissic granites and gneiss (Pascal, 1986).

\section{Land-use pattern}

Kodagu district is the largest coffee growing region in India producing about 38\% of India's coffee and is also known as the land of river Cauvery, which is a lifeline for several million farmers in the states of Karnataka and Tamil Nadu as well a source of drinking water to many towns and cities. Realizing the significance of the river Cauvery, the pioneering farmers of Kodagu have adopted a shade grown agroforestry system for cultivation of coffee, cardamom, and other plantation crops as well paddy cultivation in low lying areas. Over some time, coffee intercropped with black pepper and orange has been established as a major cropping pattern in the district. Currently, the coffee plantations of Kodagu are recognized as one of the most diverse coffee production systems in the World. The shade-grown coffee plantations cover $33 \%$ of the landscape of the district complimenting the other forested landscapes like reserve forests and protected areas, sacred forests and other wooded areas. In addition to hosting spectacular biodiversity, the landscape provides a range of ecosystem services which sustains the livelihood of the local communities (Devagiri et al., 2012).

\section{Site selection and sampling design}

The Kodagu district was divided into three bio-climatic zones mainly based on the different vegetation types viz., dry deciduous, moist deciduous and evergreen forests. In the dry deciduous vegetation zone coffee agroforests were identified and stratified in such way that the coffee farms are geographically interspersed with adjoining natural forests and based on the size of landholdings viz. large (>10 ha), medium (2.5 ha $\leq 10 \mathrm{ha})$ and (small ( $<2.5 \mathrm{ha})$ while selecting the coffee agroforest sample plots. In the above selected land-use type 50, sample plots of $40 \mathrm{~m} \mathrm{x} 40 \mathrm{~m}$ (0.16 ha.) were laid to conduct the inventory. Nested sampling approach was adopted for the collection of data on trees, shrubs and herbs as depicted in Figure 1.

Out of 50 sample plots, we laid 45 plots in coffee agroforests and five plots in adjoining forests for collection of data. In each of 0.16 ha. plots, all the woody plants were counted and identified as far as possible in-situ at species level using field keys of Pascal and Ramesh (1987), Flora of Coorg (Keshavamoorthy and Yoganarasimhan (1989) and Flora of Karnataka.

Voucher specimens of species, which could not be identified in the field, was collected for identification at the College of Forestry, Ponnampet, with the help of taxonomist. Height and girth at breast height (gbh) of all the trees with $\geq 30 \mathrm{~cm}$ gbh in each sample plots were measured by using Blume Leiss Hypsometer (which is based on the trigonometric principles) and measuring tape, respectively.

\section{Data analysis}

The stand structures of trees in coffee agroforestry were analyzed based on tree density, basal area and Importance Value Index (IVI). The IVI was calculated as the sum of average relative frequency (RF), relative density $(\mathrm{Rd})$ and relative dominance (RD) of tree species using the following formula.

$\operatorname{IVI}(\%)=(\mathrm{RF}+\mathrm{Rd}+\mathrm{RD}) / 3$ 
For the quantitative analysis of tree species in the coffee agroforests and adjoining natural forests, diversity indices employed. Species diversity indices were commonly applied for species distribution analysis which includes viz., Shannon-Wiener diversity index $\left(H^{\prime}\right)$, Simpson's (D), species richness and Jacquard's index of similarity. Shannon diversity (using natural logarithms) and Simpson index (the reciprocal form) were computed using Biodiversity Pro 2.0 software.

\section{Results and Discussion}

\section{Species diversity and vegetation structure}

Results pertaining to species richness and diversity in adjoining forests and coffee agroforests are presented in Table 1. Total of 51 tree species in coffee agroforests and 23tree species in adjoining forests were recorded. Shannon-Wiener diversity index $\left(H^{\prime}\right)$ was highest in adjoining forests (2.48) compared to the Coffee agroforests (1.98).On the other hand, Simpson's (D) values recorded in adjoining forests was higher (0.11) compared to coffee agroforests (0.28).Results revealed that a considerable number of tree species are being managed and conserved in coffee agroforests.

However, as compared to coffee agroforests in other regions, the number of tree species observed in the study area appears to be higher. Earlier study showed similar results and recorded 107 tree species in coffee plantations and 62 tree species in adjoining forests by Lopez-Gomez et al., (2008). Tree species diversity was found to be higher in a forest than in coffee farms as reported in other studies (Correia et al., 2010 and Lopez-Gomez et al., 2008). Variation in species diversity and composition between the land use systems may be attributed to management practices. In coffee agroforests, the management is protection oriented with where as in adjoining forests through protection oriented which is subjected to disturbances due to grazing, illegal felling and collection of non-timber forest products. Chima and Uwaegbulem (2012) assessed tree species populations under different land use systems in Port Harcourt region of Nigeria and reported that tree species richness was higher in biodiversity conservation area than the unprotected secondary regrowth and arable farmland. Murthy et al., (2016) reported on Western Ghats of India where the more disturbed evergreen and moist deciduous forest had low species diversity compared to less disturbed forests. In another study conducted by Devagiri et al., (2019) in coffee agroforests of Central Western Ghats region showed that coffee agroforests resembled natural forests in terms of species richness and diversity.

Across the coffee farms and adjoining natural forest in dry deciduous vegetation type, tree density and basal area varied considerably (Table 1). Tree density of 398 stems ha $^{-1}$ was recorded in coffee agroforests, while in adjoining natural forests slightly lower tree density of 323 (stems ha $^{-1}$ ) was recorded. Conversely, the basal area was found to be higher in coffee agroforests $32.36 \mathrm{~m}^{2} \mathrm{ha}^{-1}$ compared to adjoining forests $\left(30.20 \mathrm{~m}^{2} \mathrm{ha}^{-1}\right)$.

These values compare with tree density (1087 stems $\left.\mathrm{ha}^{-1}\right)$ and basal area $\left(52.60 \mathrm{~m}^{2} \mathrm{ha}^{-1}\right)$ values recorded by Swamy et al., (2000) for a humid evergreen forest in Tamil Nadu. However, the density was within the range of 257 - 664 stems $\mathrm{ha}^{-1}$ and the basal area within the range $29-42 \mathrm{~m}^{2} \mathrm{ha}^{-1}$ for agroforests, but it was on the lower side of the values recorded in natural forests as reported by Devagiri et al., (2016) and Swamy et al., (2010) for tropical evergreen forests of Western Ghats region in Karnataka. The density of trees in coffee plantations is an important factor since the shade provided by the trees affects the yield and quality. 


\section{Importance value index}

The most dominant species in coffee agroforests of the study area was Grevillea robusta with an IVI value of $90.61 \%$ followed by Ficus racemosa and Acrocarpus fraxinifolius (Table 2). The higher per cent of IVI of tree species recorded in coffee agroforests was contributed by three species out of a total of 51 tree species. Whereas, in the natural forest the dominant species recorded were Terminalia tomentosa with IVI value of $55.59 \%$ followed by Anogeissus latifolia and Lagerstroemia lanceolata (Table 2 ). The higher IVI value of these tree species is probably due to the farmer's conscious retention of trees for various benefits. An earlier study by Negawo and Beyene (2017) has also indicated similar results in coffee farms in Uganda.

\section{Effect of landholding sizes on floristic diversity and vegetation structure}

Results obtained on diversity and vegetation structure parameters as influenced by land holding sizes are presented in Table 3. Species richness and diversity was found to be higher in medium coffee farmers containing 38 tree species and diversity value of 2.00. Both small and large coffee plantations recorded a relatively lesser number of species and diversity value compared to that of mediumsized holdings. However, Simpson's dominance was found to be higher in both large and medium-size farms as compared to small holdings. Higher species richness and diversity in small size coffee plantation could be attributed to management regimes as well probably due to land tenure system.

Farmers having small holdings tend to manage their plantations intensively by retaining diverse shade trees to sustain and improve the productivity. On the contrary, basal area was found to be less in small holdings compared to medium and large holdings. It is mainly because framers owning relatively larger farm areas can afford to retain the number of large sized trees. Similarly, beta diversity values also indicate that small and medium-size farms share common species with a similarity value of 82.95 per cent. The replacement of native trees by common native and exotic fastgrowing trees is one of the major reasons for higher similarity (Elouard et al., 2000).

Fig.1 Diagram showing nested phase sampling for one site

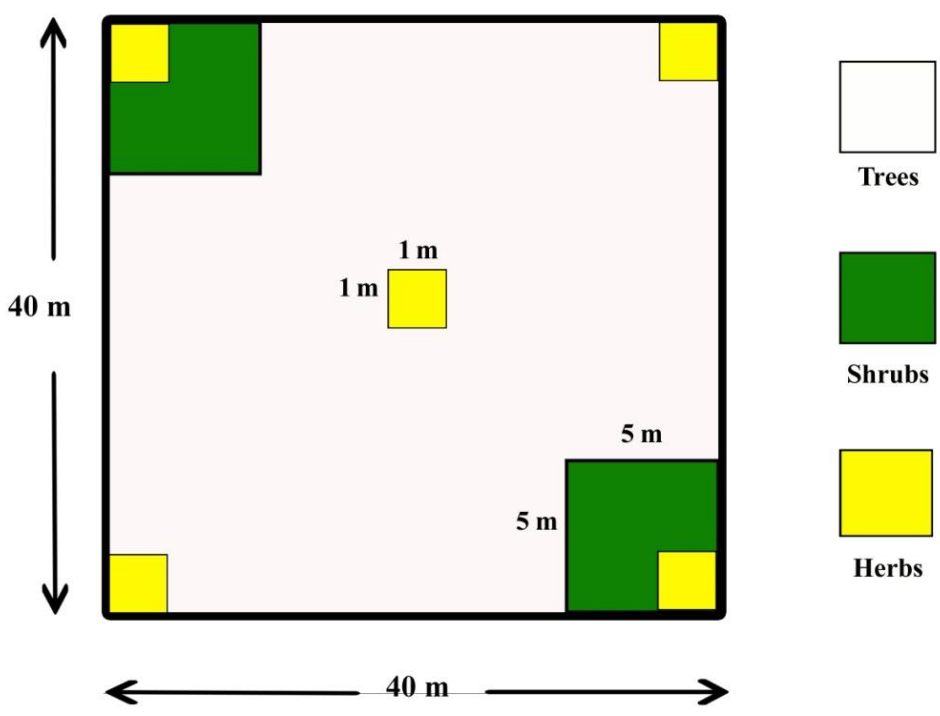


Fig.2 Effect of land holdings on girth class distribution in coffee agroforests and natural forests

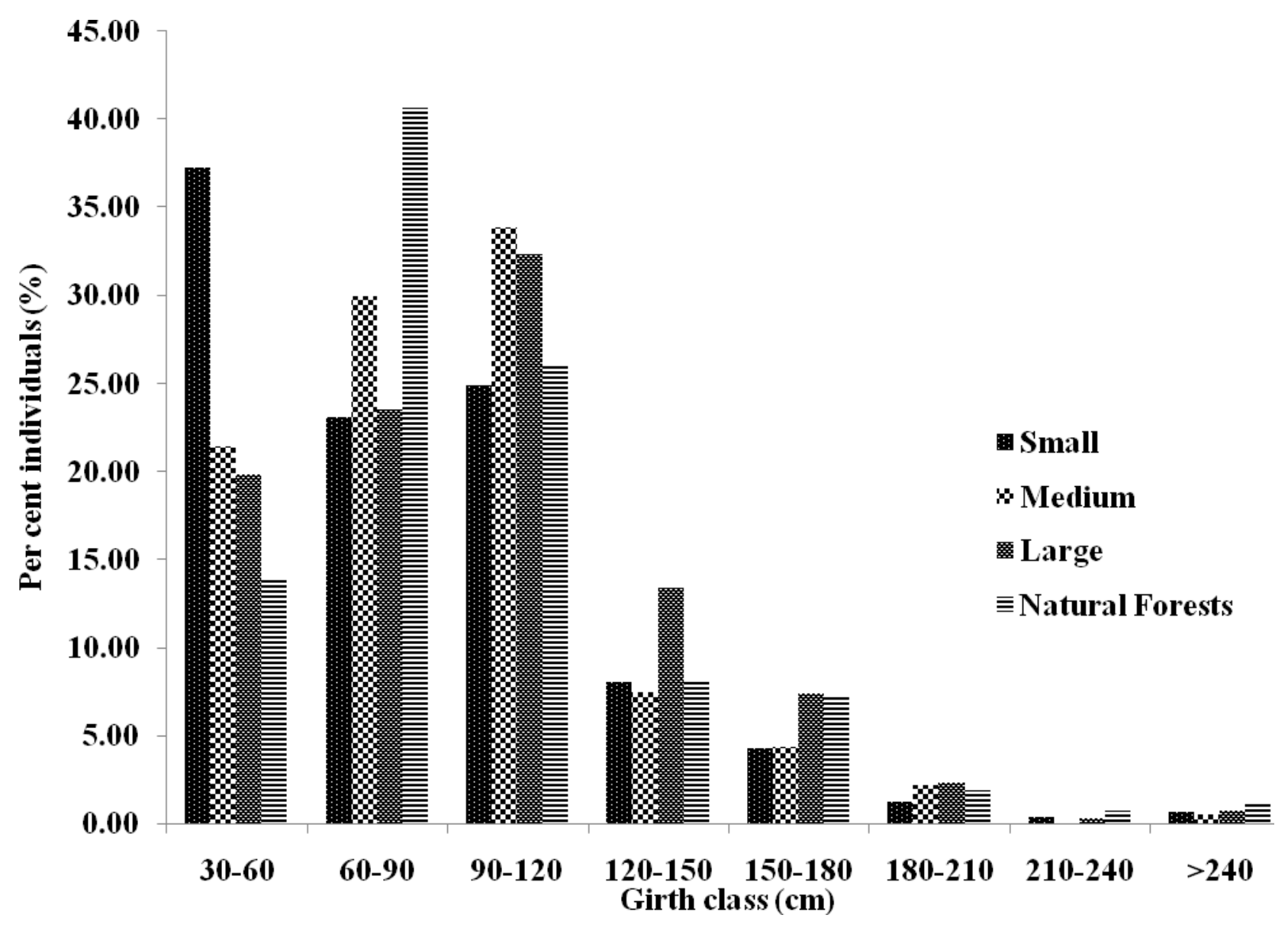

Table.1 Vegetation structure, diversity and composition in coffee agroforests and adjoining forests in dry deciduous vegetation zone (Mean \pm SE)

\begin{tabular}{|l|c|c|}
\hline Parameters & Coffee agroforests & Natural forests \\
\hline Species richness & 51 & 23 \\
\hline Shannon-Wiener diversity index $\left(\boldsymbol{H}^{\prime}\right)$ & 1.98 & 2.48 \\
\hline Simpson index $(\mathbf{D})$ & 0.28 & 0.11 \\
\hline Jacquard's index of similarity & \multicolumn{2}{|c|}{9.34} \\
\hline Tree density $\left(\mathbf{s t e m s ~}^{\mathbf{- 1}}\right)$ & $398 \pm 17.56$ & $323 \pm 16.91$ \\
\hline Basal area $\left(\mathbf{m}^{\mathbf{2}} \mathbf{~ h a ~}^{-\mathbf{1}}\right)$ & $32.36 \pm 2.11$ & $30.20 \pm 1.24$ \\
\hline
\end{tabular}


Table.2 Importance value index in coffee agroforests and adjoining forests in dry deciduous forest zone

\begin{tabular}{|l|c|c|}
\hline \multirow{2}{*}{ Species } & \multicolumn{2}{|c|}{ Importance Value Index } \\
\cline { 2 - 3 } & Adjoining forests & Coffee agroforests \\
\hline Terminalia tomentosa & $55.59(1)^{*}$ & - \\
\hline Anogeissus latifolia & $39.81(2)$ & - \\
\hline Lagerstroemia lanceolata & $31.08(3)$ & $11.93(4)$ \\
\hline Pterocarpus marsupium & $30.21(4)$ & $10.88(6)$ \\
\hline Dalbergia latifolia & $24.69(5)$ & $9.17(9)$ \\
\hline Terminalia bellirica & $22.76(6)$ & $11.21(5)$ \\
\hline Terminalia bellirica & $22.76(6)$ & $11.21(5)$ \\
\hline Adina cordifolia & $11.52(7)$ & - \\
\hline Cassia spectabilis & $11.12(8)$ & - \\
\hline Lannea coromandelica & $8.65(9)$ & - \\
\hline Hardwickia binata & $8.57(10)$ & $14.33(3)$ \\
\hline Acrocarpus fraxinifolius & - & $10.86(7)$ \\
\hline Artocarpus integrifolia & - & $9.92(8)$ \\
\hline Erythrina indica & - & $66.60(2)$ \\
\hline Ficus racemosa & - & $90.61(1)$ \\
\hline Grevillea robusta & - & $8.11(10)$ \\
\hline Syzygium cumini & - & \\
\hline *Values within the brackets indicates ranking based on IVI. & \\
\hline
\end{tabular}

Table.3 Effect of landholdings on tree diversity and structure in dry deciduous forest zone $($ Mean \pm SE)

\begin{tabular}{|l|c|c|c|}
\hline & \multicolumn{3}{|c|}{ Land holdings } \\
\hline Parameters & Large & Medium & Small \\
\hline Species richness & 27 & 38 & 30 \\
\hline Shannon-Wiener diversity index $\left(\boldsymbol{H}^{\prime}\right)$ & 1.92 & 2.00 & 2.00 \\
\hline Simpson index (D) & 0.33 & 0.29 & 0.23 \\
\hline Jacquard's similarity index & & & \\
\hline \multicolumn{1}{|c|}{$\quad$ Large } & - & 79.33 & 73.81 \\
\hline \multicolumn{1}{|c|}{ Small } & - & - & 82.95 \\
\hline Tree density $\left(\mathbf{s t e m s ~ h a m ~}^{-\mathbf{1}}\right)$ & - & - & - \\
\hline Basal area $\left(\mathbf{m}^{\mathbf{2}} \mathbf{h a}^{-\mathbf{1}}\right)$ & $370 \pm 28.31$ & $402 \pm 29.74$ & $423 \pm 47.90$ \\
\hline
\end{tabular}

Among the coffee farms of different landholding sizes in dry deciduous vegetation zone, tree density and basal area were recorded and presented in Table 3. Tree density of 423,402 and 370 stems ha ${ }^{-1}$ was recorded in small, medium and large, respectively. Similarly, basal area was recorded to be higher in large holdings (48.02 $\mathrm{m}^{2} \mathrm{ha}^{-1}$ ). Earlier results are in line with the present study conducted by Muthappa (2000). 
Girth class distribution of tree species in adjoining forests and coffee agroforests

Tree distribution in different girth class was compared between coffee agroforests and adjoining natural forests in dry deciduous vegetation type and results are depicted in Figure 2. Land holding sizes viz., small, medium and large showed a significant effect on tree distribution in different girth class. Inverse ' $J$ ' shape pattern of girth class distribution was observed in small holding coffee agroforests while in medium and large holdings the girth class distribution was showed positive and similar trend was observed in adjoining natural forests. The girth class distribution pattern of tree species in adjoining forests and different holding sizes in agroforests was positively skewed and shows the near normal distribution pattern. The absence of trees in the lower girth class indicates that tree seedlings are cleared during cultural operations. Similar results were also reported by Sathish (2005) and Basavarajappa (2017) in coffee plantations of Kodagu. Pommery and Elouard, (1997) reported that the future population (young trees) was represented by $13 \%$, present population (mature trees) $82 \%$ and past population (old trees) 5\%. Kumar et al., (1994) in their studies in home gardens of Kerala have also reported similar results.

The floristic diversity and species richness in coffee agroforests were reasonably higher than that of natural forests. However, Shannon's and Sampson's diversity indices showed that species diversity of the natural forests was higher than that of coffee agroforests. The similarity between forests and coffee agroforests in terms of species sharing was found to be $9.34 \%$. The most dominant species in coffee agroforests of the study area was Grevillea robusta with an IVI value of $90.61 \%$ and in natural forests, Terminalia tomentosa with IVI value of
55.59\%. Effect of landholdings on tree density, species richness, Shannon-Wiener diversity index $\left(H^{\prime}\right)$ and Simpson's diversity indices revealed that small sized coffee farms are more diverse than large and medium-sized coffee farms. However, basal area was found to be highest in case of large landholding. This study suggests that traditional coffee agroforests in Western Ghats region contain higher floristic diversity and these land-use systems offer greater opportunities for conservation of biodiversity.

\section{Acknowledgment}

Authors thank UAHS, Shivamogga for providing part-time deputation conduct this research as a part of my Ph.D. work. Thanks are also due to Mr. Lingaraju. S. S., CCF. Madikeri for permission and support during the field work in forest areas of Kodagu district.

\section{References}

Adams, W. M. and Hulme, D., 2001, If community conservation is the answer in Africa, what is the equations? Oryx., 35: 193-200.

Basavarajappa, S., 2017, Studies on population status and propagation of bee forage trees of coffee based agroforests. M.Sc. thesis, Univ. Agric. Hort. Sci., Shivamogga, Karnataka (India).

Berkes, F., 2009, Community conserved area: policy issues in historic and contemporary context. Conserv. Newsltr., 2: 19-24.

Bhagwat, S. A., Kushalappa, C. G., Williams, P. H. and Brown, N. D., 2005 a, The role of informal protected areas in maintaining biodiversity in the Western Ghats of India. Ecol. Soci., 10: 8-17.

Bhagwat, S. A., Kushalappa, C. G., Williams, P. H. and Brown, N. D., 2005 b, A 
landscape approach to biodiversity conservation of sacred groves in the Western Ghats of India. Conserv. Biol., 19:1853-1862.

Bhagwat, S. A., Willis, K. J., Birks, H. J. B. and Whittaker, R. J., 2008, Agroforestry: a refuge for tropical biodiversity. Tre. Ecol. Evol., 23: 261267.

CAFNET Project, 2011, the website for India: http://www.ifpindia.org/Coffee-and-

Environmental-Services-in-the-WesternGhats.html

Chima, U. D. and Uwaegbulem, C., 2012, Comparative évaluation of tree species populations under different land-use types within the University of Port Hartcourt environs. Trop. Agric. Res. Extn., $15: 1-7$.

Correia, M., Diabate, M., Beavogui, P., Guilavogui, K., Lamanda, N. and de Foresta, H., 2010, Conserving forest tree diversity in Guinee Forestière (Guinea, West Africa) : the role of coffee based agroforests. Bio Conser, $19: 1725-1747$.

Devagiri, G. M., Kushalappa, C. G., Prakash, N. A., Mohan, G. S., Raghu, H. B. and Satish, B. N., 2012, Payment for Carbon Sequestration Service (PCSS): A tool to sustainable management of Kodagu landscape in Central Western Ghats. Sero., 3: 2-7.

Devagiri, G.M., Khaple, A. K., Anithraj, H. B., Kushalappa, C. G., Krishnappa, A. K. and Mishra, S. B., 2019, Assessment of tree diversity and above ground biomass in coffee agroforest dominated tropical landscape of India's Central Western Ghats. J. For. Res., DOI 10.1007/s11676-019-00885-1.

Devagiri, G.M., Money, S., Sarnam, Singh, Dadhawal, V. K., Prasanth Patil, Khaple, A., Devakumar, S. A. and Hubballi, S., 2013, Assessment of above ground biomass and carbon pool in different vegetation types of the south western part of Karnataka, India using spectral modeling. Trop. Ecol., 54 (2): 149-165.

Elourd, C., 2000, Landscape and Society. In: Ramakrishnan, P. S., Chandrashekara, U. M., Elourd, C., Guilmoto, C. Z., Maikhuri, R. K., Rao, K. S., Sankar, S., Saxena, K. G., (Eds.) Mountain Biodiversity, Land Use Dynamics and Traditional Ecological Knowledge. Oxford and IBH Publishers New Delhi.

Keshavamoorthy, K. and Yoganarasimhan, S. N., 1989, Flora of Coorg. Vimsat Publishers, Bangalore.

Kumar, B.M., Suman, J. G. and Chinnamani, 1994, Diversity and structure of Home gardens of Kerala in peninsular India. Agrofor. Syst., 22: 263-274.

Lopez-Gomez, A. M., Williams- Linira, G., Manson, R. H., 2008, Tree species diversity and vegetation structures in shade coffee farms in Verscruz, Mexico. Agril. Ecosys. Envionr.. 124: 160-172.

Murthy, I. K., Bhat, S., Sathyanarayana, V., Patagar, S., Beerappa, M., Bhat, P. R., Bhat, D. M., Ravindranath, N. H., Khalid, M. A., Prashant, M., Iyer, S., Daniel, M.B. and Saxena, R., 2016, Vegetation structure and composition of tropical evergreen and moist deciduous forest in Uttara Kannada district, Western Ghats under different disturbance regimes. Trop. Ecolo, 57: 77-88.

Muthappa, P.P., 2000, A Resource economic study on tree diversity in coffee based plantations in the Western Ghats region of Karnataka. M.Sc. thesis, Univ. Agric. Sci., Bangalore.

Myers, N., Mittermeier, R.A., Mittermeier, C.G., da Fonseca, G.A.B. and Kent, J., 2000, Biodiversity hotspots for conservation priorities. Nature, 403: 853-858. 
Negawo, J. W., and Beyene, D. N., 2017. The role of coffee-based agroforestry systems in tree diversity conservation in Eastern Uganda. J. Land. Ecol., 10:618.

Pascal, J. P. and Pelissier, R., 1996. Structure and floristic composition of a tropical evergreen forest in South-West India. $J$. Trop. Ecol., 12: 191-214.

Pascal, J. P. and Ramesh, B. R., 1987, A Field Key to the Trees and Lianas of Evergreen Forest of Western Ghats (India), French Institute, Pondicherry, India.

Pascal, J. P., 1986, Explanatory Booklet on the Forest Maps of South India. French Institute, Pondicherry, India, pp. 1-52.

Pommery, de H. and Elouard, C., 1997. A report on Assessment of the diversity and structure of two coffee-based agroforestry systems Balmany and
Siddapur. French Institute Pondicherry, Pondicherry.

Sathish, B.N., 2005, Studies on tree diversity in different land tenure systems in Kodagu, Central Western Ghats. M.Sc. thesis, Univ. Agric. Sci., Bengaluru, Karnataka (India).

Swamy, P.S., Sundarapandian, S.M., Chandrashekar, P. and Chandrashekaran, S., 2000, Plant species diversity and tree population structure of humid tropical forest in Tamil Nadu, India. Biodivers. Conserv. 9:1643-1669.

Swamy, S.L., Dutt, C.B.S., Murthy, M.S.R., Alka M. and Bargali, S.S., 2010, Floristic and dry matter dynamics of tropical wet evergreen forests of Western Ghats, India. Curr. Sci., 99: 353-364.

\section{How to cite this article:}

Baliram G. Nayak and Raju L. Chavan. 2019. Floristic Diversity and Vegetation Structure of Coffee Agroforests in Relation to Natural Forests in Dry Deciduous Vegetation Zone in Central Western Ghats of India. Int.J.Curr.Microbiol.App.Sci. 8(07): 2357-2366.

doi: https://doi.org/10.20546/ijcmas.2019.807.289 